\title{
Toxicity of Spathodea campanulata P Beauvois (Scrophulariales: Bignoniaceae) aqueous extracts against immature stages of Anopheles albimanus (Diptera: Culicidae) under laboratory conditions
}

\author{
This article was published in the following Dove Press journal: \\ Research and Reports in Tropical Medicine \\ 2 December 2010 \\ Number of times this article has been viewed
}

Jose Luis Torres-Estrada'

Julio Cesar Velazquez

Gonzalez'

Silvany M Rios Delgado'

María Guadalupe

Vazquez-Martinez'

R Patricia Penilla-Navarro'

Americo D Rodriguez'

'Centro Regional de Investigación en Salud Pública, Instituto Nacional de Salud Pública, Colonia Centro, Tapachula, Chiapas, México
Correspondence: María Guadalupe Vázquez-Martínez

Centro Regional de Investigación en Salud Pública, Instituto Nacional de Salud

Pública, 4a. Norte y 19 Poniente

s/n, Colonia Centro, C.P. 30700,

Tapachula, Chiapas, México

Tel + 529626250044

Fax +52962 6265782

Email mguadalu@insp.mx
Purpose: To determine the effects of African tulip Spathodea campanulata aqueous extracts on every immature stage of Anopheles albimanus under laboratory conditions.

Methods: The extract was obtained making an incision on the apical part of prefloral bulbs, and two sets of dilutions with distilled water were prepared. The first set was used at $50 \%, 20 \%$, $10 \%, 5 \%$, and $2.5 \%$ concentrations in bioassays to test its effect on egg-hatching inhibition. The second set was used at $10 \%, 5 \%, 1 \%, 0.1 \%$, and $0.01 \%$ to test toxicity on larvae and pupae. Also, residual efficacy and lethal time (LT) were estimated.

Results: The highest inhibition (87.5\%) recorded for egg hatching was at a $50 \%$ concentration. Third and fourth instar larvae and pupae were the most susceptible to $10 \%$ and $5 \%$ of S. campanulata aqueous extracts, with $98.3 \%-100 \%$ mortality. The residual activity with $10 \%$ concentration persisted 7 days, with 100\% mortality, and LT for 99\% mortality $\left(\mathrm{LT}_{99}\right)$ was 2.28 hours on third instar larvae, 1.7 hours on fourth instar larvae, and 2.25 hours on pupae.

Conclusion: $S$. campanulata extracts are promising as biolarvicides. Further toxicological and chromatographic studies are encouraged and needed.

Keywords: African tulip, botanical insecticides, malaria, mosquitoes

\section{Introduction}

Malaria is still a major vector-borne disease affecting humans. Anopheles albimanus Wiedemann is the main malaria vector in coastal areas in Mexico and Central America. ${ }^{1}$ The use of insecticides continues to be the most effective control method; however, this species has developed multiple resistance to most insecticides used by public health institutions, which can hinder the control of malaria in endemic areas. ${ }^{2-5}$ The use of insecticides can also damage the environment and a wide variety of nontarget organisms. ${ }^{6}$ Based on such difficulties and limitations in the use of insecticides for the control of mosquito vectors, the search for new and less aggressive alternatives, such as toxic compounds from plant extracts, is a good choice. ${ }^{7,8}$

Several plant extracts that have served as a basis in developing synthetic insecticides have been tested in the past. Spathodea campanulata (African tulip tree) could be a good candidate for $A$. albimanus control, since it has been proven to contain an alkaloid toxic to Aedes fluviatilis larvae. ${ }^{9,10}$ However, the effectiveness against the immature stages of the malaria mosquito has not been tested. $S$. campanulata is an established introduced species currently widely distributed in Mexico as an ornamental tree. 
Herein, we present the results about the efficacy of $S$. campanulata aqueous extracts against immature stages of $A$. albimanus.

\section{Materials and methods Mosquitoes}

Immature stages (eggs, first, second, third, and fourth instar larvae and pupae) were obtained from a colony established in the Centro Regional de Investigacion en Salud Publica and maintained at $28 \pm 2{ }^{\circ} \mathrm{C}$ temperatures and $75 \pm 5 \%$ relative humidity. ${ }^{11}$

\section{Aqueous extracts}

Prefloral bulbs of $S$. campanulata were collected from cultivated trees in the area of Tapachula City, Chiapas, Mexico. The extract was obtained by making an incision on the apical part of the bulbs, and the liquid obtained was kept in $1 \mathrm{~L}$ glass containers. Two sets of dilutions with distilled water were prepared, one to test whether an effect on egg-hatching inhibition exists, and the second to test toxicity on larvae and pupae.

\section{Egg-hatching inhibition}

The efficacy of $50 \%, 20 \%, 10 \%, 5 \%$, and $2.5 \%$ concentrations of $S$. campanulata extracts to inhibit $A$. albimanus eggs from hatching was examined. For each concentration, four replicates of 20 eggs were exposed to $S$. campanulata in plastic containers. As a control, five replicates (one for each concentration) of 20 eggs were exposed to distilled water without $S$. campanulata extracts. Egg hatching in containers was recorded at 24 and 48 hours, using a dissection microscope to observe the first instar larvae.

\section{Toxicity against larvae and pupae}

Bioassays to determine the lethal concentration of the S. campanulata extracts (at 10\%, 5\%, 1\%, 0.1\%, and $0.01 \%$ ) were conducted following the World Health Organization protocol to test susceptibility on mosquito larvae (first, second, third, and fourth instar) and pupae. ${ }^{12}$ In total, 6400 larvae were used for the bioassays: four replicates of 20 larvae per container (80) per each instar (320) per each one of the five concentrations (1600), with four experiment replicates (6400 in total). For the pupae bioassays, one experiment was carried out with the five concentrations mentioned above with four replicates, using 400 pupae. As a control, for each experiment, larvae and pupae were exposed to distilled water without the $S$. campanulata aqueous extract. Mortality was assessed 24 hours after the treatment.

\section{Residual efficacy of aqueous extracts}

To determine the residual efficacy of $S$. campanulata aqueous extracts, 100 of the most susceptible instar larvae were exposed every day to the concentration with the highest mortality, and distilled water without the aqueous extract was used as a control. Mortality was recorded daily, and dead individuals were replaced in the treatment until the observed mortality decreased to less than $80 \%$. A new set of individuals were replaced every day in the control containers according to the treatment. This experiment was carried out in two replicates.

\section{Lethal time}

The lethal time for $99 \%$ mortality $\left(\mathrm{LT}_{99}\right)$ was determined at $0.5,1.0,1.5,2.0$, and 24 hours in $250 \mathrm{~mL}$ of the $S$. campanulata aqueous extract, with the highest mortality reported in each immature stage.

\section{Statistical analysis}

The percentage of larval mortality and egg-hatching inhibition was calculated, and the data were normalized by transformation to the arcsine square root. ${ }^{13}$ The efficacy of each concentration was analyzed by a two-way analysis of variance (ANOVA) and Tukey's multiple contrasts tests. ${ }^{14}$ LT results were analyzed with a Probit test (version 1.5).

\section{Results}

\section{Egg-hatching inhibition}

All the $S$. campanulata aqueous extracts tested inhibited egg hatching (36\%-87.5\%) (see Figure 1), with significant differences observed against the control $(P<0.05)$. Post hoc analysis revealed that exposure to the highest concentration $(50 \%)$ resulted in statistically higher inhibition $(87.5 \pm 7.1 \%)$ compared with the rest of the concentrations ( $\mathrm{F}=40.39$; $\mathrm{df}=8 ; P=0.0001)$.

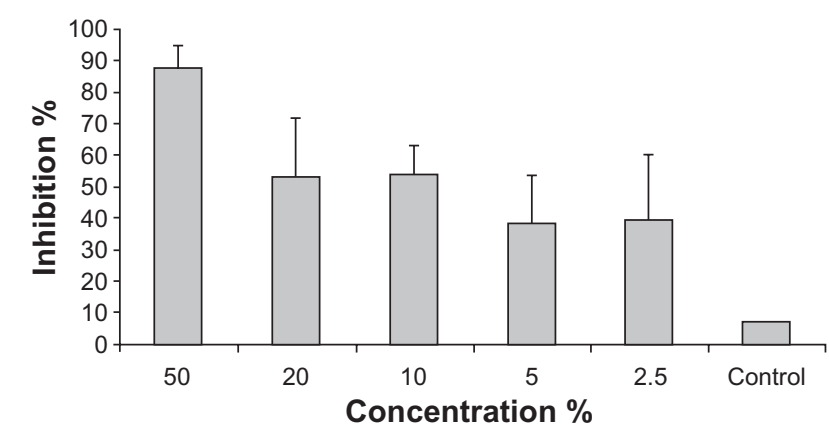

Figure I Egg-hatching inhibition by Anopheles albimanus caused by several concentrations of Spathodea campanulata aqueous extracts. 


\section{Toxicity against larvae and pupae}

Toxicity of $S$. campanulata aqueous extracts statistically varied according to the concentration tested and the immature stage of A. albimanus $(P<0.05)$ (see Figure 2). Although the lowest mortality was observed always in the first instar stage compared with the rest of the immature stages in any of the extract concentrations tested $(P<0.05)$, its highest mortality $(36.6 \pm 15.8 \%)$ was also recorded with the highest concentration aqueous extract tested (10\%) (see Figure 2). No statistical differences in percentage of toxicity were observed between the $10 \%$ and the $5 \%$ concentrations, but differences were observed between these concentrations and the rest of the concentrations $(1 \%, 0.1 \%$, and $0.01 \% ; P<0.05)$ (see Figure 2). Similar percentage mortalities were found with the $10 \%$ and the $5 \%$ extract concentrations $(P>0.05)$ for the second $(91.6 \%$ and $89.9 \%$, respectively), third ( $98.43 \%$ for both), fourth (100\% and $97.5 \%$, respectively), and pupae (100\% for both) stages.

\section{Residual efficacy of aqueous extracts}

The fourth instar stage was the most susceptible at the $10 \%$ concentration. The S. campanulata $10 \%$ aqueous extract caused $100 \%$ mortality in this A. albimanus instar during 7 days, decreasing to $80 \%$ after the eighth day (Figure 3).

\section{Lethal time}

The $\mathrm{LT}_{99}$ of $10 \% \mathrm{~S}$. campanulata aqueous extracts determined was 2.28 hours, when $99 \%$ of the third instar larvae population died after exposure. This extract concentration also killed $99 \%$ of the fourth instar larvae and pupae population after 1.7 hours and 2.25 hours, respectively; while the first and second instar larvae population required 63.8 and 25.9 hours, respectively (Figure 4).

\section{Discussion}

Aqueous extracts were tested on A. albimanus egg, larvae, and pupae; the eggs being the less susceptible. The aqueous extracts at $10 \%$ and $5 \%$ concentrations killed between $89.9 \%$ and $100 \%$ of the A. albimanus immature stage populations, except for the first instar larvae stage, where mortality ranges were less than $40 \%$. However, we highlight the effect with both extract concentrations on the pupae stage, where $100 \%$ mortality was obtained for all replicates.

Toxicity of African tulip flowers has been reported for Meliponinae, Diptera, Vespidae, Formicidae, and Orthoptera. ${ }^{15}$ Particularly, the effects of $S$. campanulata on A. fluviatilis were previously reported, as its antimalarial activity with stem bark extracts was also reported on Plasmodium berghei berghei in mice., ${ }^{916}$ Our results have demonstrated that $S$. campanulata is a promising product

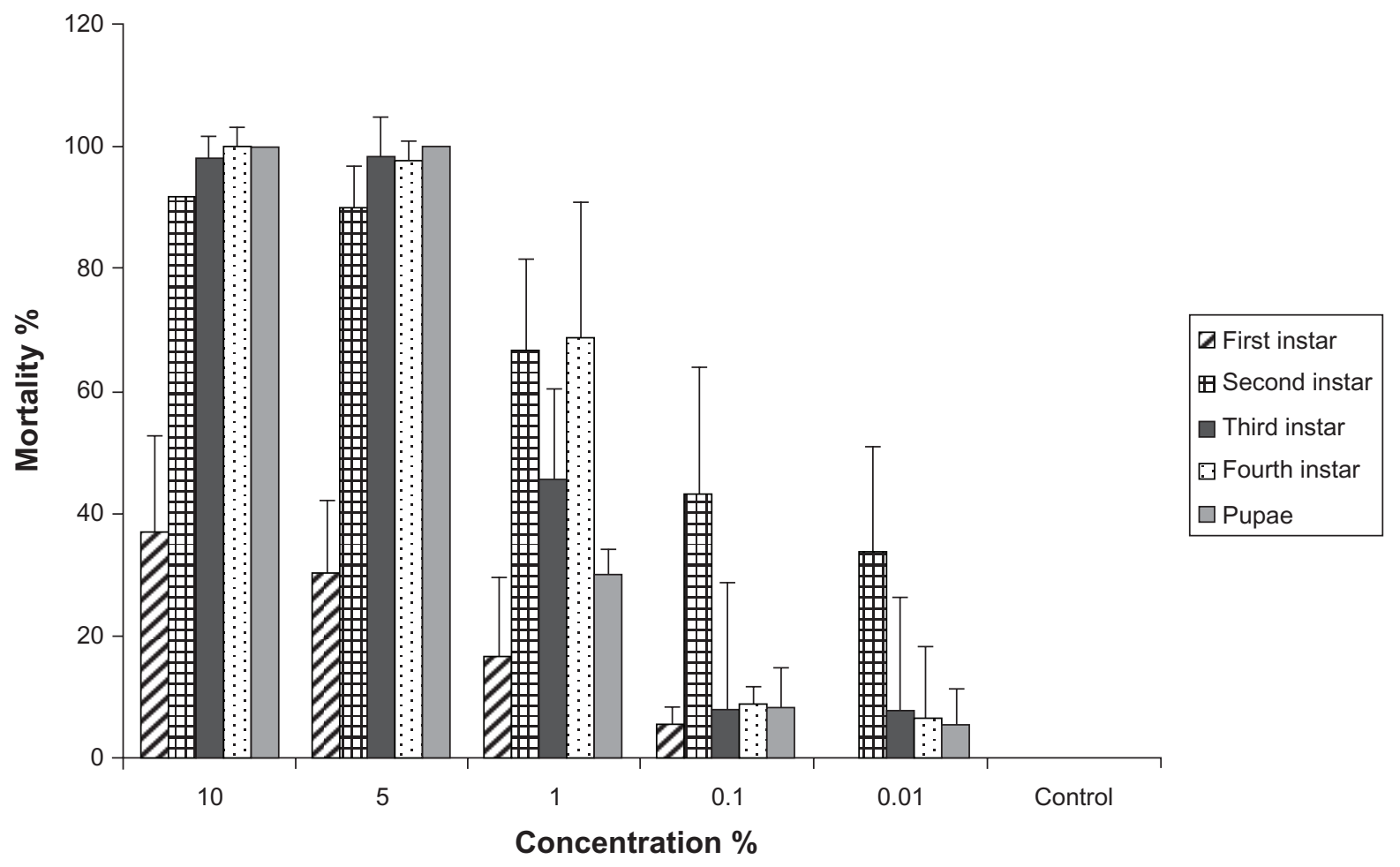

Figure 2 Effects of Spathodea campanulata aqueous extracts on immature stages of Anopheles albimanus. 


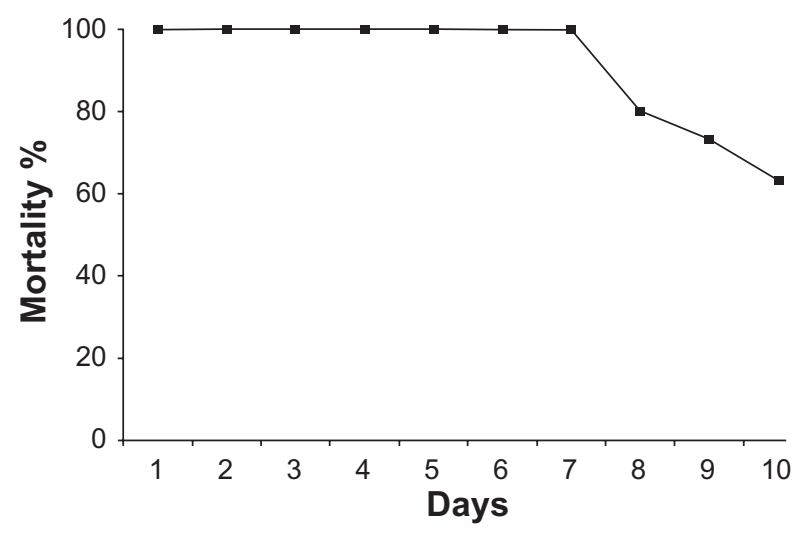

Figure 3 Residual efficacy of Spathodea campanulata aqueous extracts on fourth instar larvae exposed at a 10\% concentration.

for malaria vector control in Mexico and elsewhere, where A. albimanus may still be causing problems.

Egg-hatching inhibition was previously reported on several mosquito species caused by terpenic compound extracts from various plants. ${ }^{17}$ Also, an ovicide effect of Azadirachta indica, a plant with various proprieties such as antifeedancy, growth regulation, fecundity suppression, male sterility, oviposition repellency, changes in biological fitness such as loss of flying ability, immunodepression, enzyme inhibition, splitting of biological rhythms, and so forth against insects has been reported against Culex quinquefasciatus and C. tarsalis. ${ }^{18,19}$ In this study, although at a high concentration (50\%), aqueous extract of S. campanulata caused $87.5 \%$ egg-hatching inhibition.

LT observed on the different immature stages of A. albimanus were consistent with our susceptibility

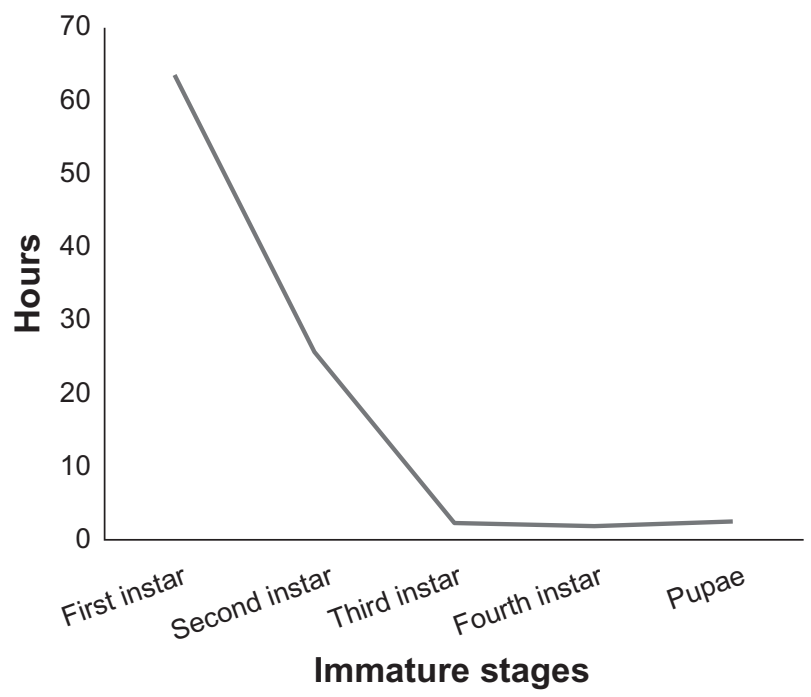

Figure 4 Lethal time of Spathodea campanulata aqueous extracts on different instar larvae and pupae exposed at a 10\% concentration. results, where the latest stages (third and fourth instar and pupae) were more susceptible to the $10 \%$ concentration, giving the $\mathrm{LT}_{99}$ at $2.28,1.7$, and 2.25 hours, respectively, as compared with first and second instar, which needed 63.8 and 25.9 hours, respectively. It is clear that the potency of the extract is higher at later instars, which suggests that at the earlier stages the presence of a specific age-related protein may give protection against the active compound. Further proteomic studies could help to elucidate the level at which the extract is acting.

Larvicidal activity of Quillaja saponaria commercial bark saponin extract, which was studied on third and fourth instar larvae of $A$. aegypti and $C$. pipiens, showed $100 \%$ mortality after $1-5$ days at 800 and $1000 \mathrm{mg} / \mathrm{L}$ doses, respectively. ${ }^{20}$ Other studies under laboratory and semi-field conditions ${ }^{21}$ demonstrated that the activity of the Calophyllum inophyllum seed and leaf extracts as the leaf extracts of $R$. nasutus persisted for up to 10 days. On the other hand, insect growth regulator novaluron-controlled immature Culex mosquitoes for up to 14 days at 1.25, 2.5, and $5 \mathrm{ppb}$ in the microcosms, and for up to 7 days using 1,5 , and $10 \mathrm{mg} / \mathrm{m}^{2}$ doses. ${ }^{22}$ The larvicide effect of $10 \%$ concentration of $S$. campanulata extract on fourth instar A. albimanus lasted 7 days, which is in between the residual efficacy of the novaluron and the $Q$. saponaria extract. Further studies are needed to purify the extract and get a more concentrated active compound as well as to discover the active ingredient or ingredients for its synthesis. Either approach would lead to the possibility of formulating a more operationally feasible product.

\section{Conclusion}

The results of this study suggest that $S$. campanulata aqueous extracts are promising as larvicides against A. albimanus and might be useful in the search for new natural larvicidal compounds. However, more studies are needed regarding the mode of action and identification of the active compounds in $S$. campanulata, as well as its effects on nontarget organisms. Once its impact on nontarget organisms is elucidated, and given the relatively easy way to prepare $S$. campanulata aqueous extracts, a community engaged approach could be implemented as an alternative in villages within endemic malaria areas of Mexico and worldwide. This would help to empower villagers and could be included as an innovative component of control programs where community involvement and reduction of chemical control are encouraged. 


\section{Acknowledgment/disclosure}

This study was supported by Centro Regional de Investigación en Salud Pública/Instituto Nacional de Salud Pública. The authors report no conflicts of interest in this work.

\section{References}

1. Rodríguez MH, Loyola EG. Situación Epidemiológica Actual y Perspectivas de Investigación Entomológica del Paludismo en México. Oaxtepec, Morelos, México: Memorias del IV Simposio Nacional de Entomología Médica y Veterinaria; 1989:15-40.

2. Brogdon WG, McAllister JC, Corwin AM, Cordon-Rosales C. Independent selection of multiple mechanisms for pyrethroid resistance in Guatemalan Anopheles albimanus (Diptera: Culicidae). J Econ Entomol. 1999;92:298-302.

3. Frederickson EC. Bionomics and Control of Anopheles albimanus. Technical Paper No. 34. Geneva, Switzerland: Pan American Health Organization, World Health Organization; 1993.

4. Arredondo-Jiménez JI, Rodríguez MH, Bown DN, et al. Indoor low-volume insecticide spray for the control of Anopheles albimanus: village-scale trial of bendiocarb, deltametrin and cyfluthrin. JAm Mosq Control Assoc. 1993;9:210-220.

5. Penilla-Navarro RP, Rodriguez AD, Hemingway J, et al. Resistance management strategies in malaria vector mosquito control. Baseline data for a large-scale field trial against Anopheles albimanus in Mexico. Med Vet Entomol. 1998;12:217-233.

6. Matsumura F. Toxicology of Insecticides. New York, NY: Plenum Press; 1975:1-4.

7. Hartzell A, Wilcoxon F. A survey of plant products for insecticidal properties. Contrib Boyce Thompson Inst. 1941;12:127-241.

8. Sukumar K, Perich MJ, Boobar LR. Botanical derivates in mosquito control: a review. J Am Mosq Control Assoc. 1991;7:210-257.

9. Consoli RAGB, Mendés NM, Pereira JP, et al. Influencia de diversos derivados de vegetais na sobrevida das larvas de Aedes fluviatilis (Lutz) (Diptera: Culicidae) en laboratorio. Men Inst Oswaldo Cruz. 1988; 83:87-93.

10. Consoli RAGB, Mendés NM, Pereira JP, et al. Influence of several plant extracts on the oviposition behavior of Aedes fluviatilis (Lutz) (Diptera: Culicidae) in the laboratory. Men Inst Oswaldo Cruz. 1989; 84:47-51.
11. Chang AST, Rodríguez MH, Torres JA, et al. Susceptibility of three laboratory strains of Anopheles albimanus (Diptera: Culicidae) to coindigenous Plasmodium vivax in southern Mexico. J Med Entomol. 1994;31:400-403.

12. World Health Organization. Instructions for Determining the Susceptibility or Resistance of Mosquito Larval to Insecticides. Geneva, Switzerland: World Health Organization/Organisation Mondiale de la Santé - Village Bednet Committee; 1981:807.

13. Sokal RR, Rohlf JF. Biometry: The principals and practice of statistics in biological research. 3rd ed. San Francisco, CA: WH Freeman and Company; 1995.

14. SAS Institute. SAS for Windows version 6.11. Cary, NC: SAS Institute; 1995.

15. Trigo JR, Santos W. Insect mortality in Spathodea campanulata Beauv. (Bignoniaceae) flowers. Rev Brasileira Biol. 2000;60: 537-608.

16. Makinde JM, Amusan OO, Adesogan EK. The antimalarial activity of Spathodea campanulata stem bark extract on Plasmodium berghei berghei in mice. Planta Med. 1988;54:122-125.

17. Saxena KN, Sharma RN. Embryonic inhibition and oviposition induction in Aedes aegypti by certain terpenoids. J Econom Entomol. 1972;65:1588-1591.

18. Su T, Mulla MS. Antifeedancy of neem products containing Azadirachtin against Culex tarsalis and Culex quinquefasciatus (Diptera: Culicidae). J Vector Ecol. 1998;23:114-122.

19. Mulla MS, Su T. Activity and biological effects of neem products against arthropods of medical and veterinary importance. J Am Mosq Control Assoc. 1999;15:133-152.

20. Pelah D, Abramovich Z, Markus A, et al. The use of commercial saponin from Quillaja saponaria bark as a natural larvicidal agent against Aedes aegypti and Culex pipiens. J Ethnopharmacol. 2002;81: 407-409.

21. Pushpalatha E, Muthukrishnan J. Efficacy of two tropical plant extracts for the control of mosquitoes. J Appl Entomol. 1999;123: 369-373.

22. Su T, Mulla MS, Zaim M. Laboratory and field evaluations of novaluron, a new insect growth regulator (IGR), against Culex mosquitoes. J Am Mosq Control Assoc. 2003;19:408-418.
Research and Reports in Tropical Medicine

\section{Publish your work in this journal}

Research and Reports in Tropical Medicine is an international, peerreviewed, open access journal publishing original research, case reports, editorials, reviews and commentaries on all areas of tropical medicine, including: Diseases and medicine in tropical regions; Entomology; Epidemiology; Health economics issues; Infectious disease; Laboratory

\section{Dovepress}

science and new technology in tropical medicine; Parasitology; Public health medicine/health care policy in tropical regions; and Microbiology. The manuscript management system is completely online and includes a very quick and fair peer-review system. Visit http://www.dovepress. com/testimonials.php to read real quotes from published authors. 